\title{
Energy Efficiency and Conservation Economies
}

\author{
Dmitriy Evgenevich Sklyarov, Evgeny Fedorovich Kustov, \\ Valery Konstantinovich Lozenko \\ National Research University “MEI”, Moscow, Russia \\ Email: Sklyarov.d.e@gmail.com
}

Received 10 March 2015; accepted 23 June 2015; published 26 June 2015

Copyright (C) 2015 by authors and Scientific Research Publishing Inc.

This work is licensed under the Creative Commons Attribution International License (CC BY). http://creativecommons.org/licenses/by/4.0/

(c) (i) Open Access

\begin{abstract}
Economic systems exist under the condition of receipt and expenditure of energy. Energy consumption is a necessary condition for the existence and functioning of any scale economic systems: macroeconomics, microeconomics, economic regions, or the world economy. However, the energy conditions of existence of economic systems differ from these conditions for other systems. So biological systems are dissipative systems, which exist under condition of energy consumption and expenditure. Economic system exists not only because of energy consumption, but also because of energy production.
\end{abstract}

\section{Keywords}

Energy Efficiency, Energy Conservation, Matrix Method, Matrix

\section{Introduction}

Economic system operates in that scale in which it is able to produce energy and get access to energy. Moreover, the receipt and consumption of energy at the economic system operation is mainly determined by, the level of energy production from energy sources, as this level is determined by the level of industries energy consumption and enterprises of the economy.

Nowadays economic systems do not produce energy in reserve, when only began creation of energy storage system. However, these systems are designed to dampen uneven temporal energy consumption and for saving energy.

The law of conservation of energy economies is formatted as follows: The levels of energy consumption and receiving of economic system are equal.

It is assumed that the scale and depth of the economic transformation depends on the levels of capital and labor. This makes sense to replace this dyad on the triad: the economy is determined by the expenditure of labor, 
capital and energy.

But, it is necessary to include also informational factor that has especial condition for functioning of the economy. These entropic factors determine the direction of the economic system development. System passes from a less to a more probable state or state with a higher information level. But it is a separate and very serious issue, which is not covered in this article.

Drastic increase in energy efficiency and reducing energy intensity of gross domestic product (GDP)-is a priority task of many developed and developing countries. Thus, on the UN General Assembly in New York in July of this year, UN chief Ban Ki-moon announced the target-reducing energy intensity of world GDP in 2050 to $50 \%$ [1]. Ambitious goals for this account have already mapped out for themselves, a lot of countries. Thus, the EU plans to reduce the energy intensity GDP by $20 \%$, China - $40 \%$ [1].

The interest of the international community to posed problem is defined, by the fact that in many countries of the world, among which are Denmark, Sweden, Spain, Ireland, the US, South Korea, and others, have developed national standards for energy management. Among generalizing standards a relatively new European standard EN 16001 emphasize, published by the British Standards Institution BSI July 1, 2009. This standard is a prototype of an even more universal international standard (MS) ISO 50001:2011 [2], designed by Technical Committee "Energy Management" of the International Organization for Standardization (ISO). This standard is intended to provide guidance for the organizations to establish the systems and processes necessary to improve energy performance, including energy efficiency, energy use and energy consumption, and the subsequent reduction in financial expenses and reduce the negative impact on the environment through systematic management of energy (energy management) based on the principle of PDCA: Plan-Action-Check-Impact.

MS ISO 50001:2011 formulates requirements for the management system of a separate organization. However, given the objectively existing noted above, the triad (labor, capital and energy) we must make an assumption about the existence of a mutual influence on each other's organizations and industries [3] in implementing energy efficiency programs. Let us examine this question in more detail.

In [4] [5] was developed model of "input-output, price-value added" based on the matrix method, allowing to carry out an economic analysis based on the specific structure of the economy or mutually closed part of it. In [6]-[8], this model was used to analyze the influence of corruption and environmental factors on the functioning of the various sectors of the economy.

In many cases, the diversified structure of economic relations allows folding of this structure to the two-sector model. Under the two sector models we can analyze the global economy and developing countries economy, industrial production and the ecology of the environment, the economic relationship of the main production and industrial infrastructure, consider the financial and real sectors of the economy [9] [10].

Similarly, from the whole industries structure we can distinguish energy production sector and consider energy efficiency problems from the analysis of production and energy supply other sectors of the economy and households (objects that consume energy, but do not produce products under demand) [11] [12].

Matrix method of energy efficiency problems analysis provides a basic relation of energy resources production and consumption by the example of the economic relationship of the energy and real economy sectors and households. Using the matrix method can be diversified economic system and the energy industry to reduce to a two-sector model and analyze the conditions for their mutual development and change in the structural indicators.

\section{The Matrix Equations of Two Sector Economy of Energy Production and Consumption. The Definition of "Energy Conservation"}

Consider the simplest case, when the first sector is the energy production, and the second sector is the industry production and at the same time energy consumer. Total economic matrix equation can be written in the following form:

$$
(\boldsymbol{I}-\boldsymbol{A}) Y=C,
$$

where $\boldsymbol{I}$ : the identity matrix, $\boldsymbol{A}$ : technological matrix of expenses of two sectors, $Y$ : output vector of products of each sector , $C$ : vector of external supplies of two sectors productions.

Technological matrix of two types of products and expenses is:

$$
\left|\begin{array}{ll}
a_{11} & a_{21} \\
a_{12} & a_{22}
\end{array}\right| .
$$


The coefficient $a_{11}$ determines its own specific expenses per unit of energy production. The coefficient $a_{22}$ determines its own second sector expenses or energy consumer specific deliveries per unit of the second sector production.

The coefficient $a_{11}$ and $a_{22}$ are dimensionless quantities determined by technology. The coefficients $\mathrm{a}_{11}$ determines first sector own expenses or a share of his full production level which first sector left to itself. This coefficient is less than unity.

The coefficient $a_{21}$ determines the energy deliveries per unit of the second sector output, has the dimension of energy unit on second sector output-energy intensity of second sector products. If you multiply this ratio on release a second sector, you will get full energy deliveries to the second sector.

The coefficient $a_{12}$ determines expenses of the second industry sector on produced energy unit of first sector, has the dimension of the second sector output unit per energy sector output unit-energy efficiency of second industry products. If you multiply this ratio for the full release of the energy industry, it will be expenses of a second sector on the received energy.

The first line of technological matrix refers to the sector of energy production and describes the energy consumption for its own production and supply it to the consumer sector.

The second line of technological matrix refers to the second manufacturing sector and describes its expenses on energy consumption.

The Matrix “expenses-production” of products and energy will be:

$$
\left|\begin{array}{cc}
1-a_{11} & -a_{21} \\
-a_{12} & 1-a_{22}
\end{array}\right| .
$$

Here, the units represent total energy production and full production release of the second sector of industry consumer energy. If you multiply this matrix by a column vector of production of two sectors $Y_{1}$ and $Y_{2}$ we get the column vector of energy supplies $C_{1}$ and of products industry $C_{2}$ to second external customers and households.

$C_{1}$ external energy supply to consumers in the structure of the economy can be seen as energy conservation. If the same issue $Y_{2}$ of the second sector the value $C_{1}$ of external energy supply to consumers will increase, it will lead to lower energy consumption in the industry or to save energy. Energy saving in this definition refers to the production sectors of the economy.

Energy savings from energy consumers does not make sense to consider, because the energy is a product that the consumer buys. As it spends purchased energy that is his business and for the functioning of the economy should not be restricted in the use of consumer's goods. If the more consumer will use the product from the market, the economy will be more effective. In a large sense, energy efficiency should not exist under normal market-oriented economy. It can exist in the economy of social overloaded type, when the energy is supplied at prices below the expenses of energy. For example, in the northern areas with poor people who can not pay all the energy and the state should supply energy at the expense of public spending. Then it should be introduced energy saving in households.

Energy savings depend on the magnitude of the coefficient $a_{21}$ of technological matrix, that is the specific waste of energy per unit of output energy consumer. If we write the Equation (1) in its entirety, we find the following form of the equation

$$
\left|\begin{array}{cc}
1-a_{11} & -a_{21} \\
-a_{12} & 1-a_{22}
\end{array}\right| \times\left|\begin{array}{c}
Y_{1} \\
Y_{2}
\end{array}\right|=\left|\begin{array}{c}
C_{1} \\
C_{2}
\end{array}\right| .
$$

This matrix equation can be represented as a system of two equations:

$$
\begin{aligned}
& \left(1-a_{11}\right) Y_{1}-a_{21} Y_{2}=C_{1} \\
& -a_{12} Y_{1}+\left(1-a_{22}\right) Y_{2}=C_{2}
\end{aligned}
$$

The direct solution of a system of two equations for $Y_{1}$ and $Y_{2}$ leads to the following result. for energy production:

$$
\left(1-a_{11}-\frac{a_{21} a_{12}}{1-a_{22}}\right) Y_{1}=C_{1}+\frac{a_{21}}{1-a_{22}} C_{2}
$$


For the second sector:

$$
\left(1-a_{22}-\frac{a_{21} a_{12}}{\left(1-a_{11}\right)}\right) Y_{2}=C_{2}+\frac{a_{12}}{\left(1-a_{11}\right)} C_{1}
$$

From Equation (3) energy savings equal to $C_{1}$ :

$$
C_{1}=\left(1-a_{11}-\frac{a_{21} a_{12}}{1-a_{22}}\right) Y_{1}-\frac{a_{21}}{1-a_{22}} C_{2}
$$

The relative energy savings $c_{1}=\frac{C_{1}}{Y_{1}}$ relative to the total production of the energy industry will be determined by the following formula.

$$
c_{1}=\left(1-a_{11}-\frac{a_{12}}{1-a_{22}} a_{21}\right)-\frac{a_{21}}{1-a_{22}} c_{2}
$$

where $c_{2}=\frac{C_{2}}{Y_{1}}$ the relative supply of products or delivery of the second industry specific customers on the full energy.

The dependence of the coefficient of relative energy efficiency from energy consumption coefficient $a_{21}$ by energy consumers for several values of the relative supply of its products $c_{2}=0,0.2,0.4,0.6,0.8$ with values of technological matrix $a_{11}=a_{22}=0, a_{12}=0.2$ is shown on Figure 1 \& Figure 2 .

The relative energy efficiency decreased linearly (Equation (6)) with increasing energy expenses $a_{21}$ of consumers. At the same time increasing $c_{2}$ or the relative supply of energy consumers of their products to the market energy efficiency decreases with the linear trend.

\section{The Equations of Energy Efficiency of Economy Sectors}

At production, each industry use energy depending on their price and energy efficiency in sectors. Technological

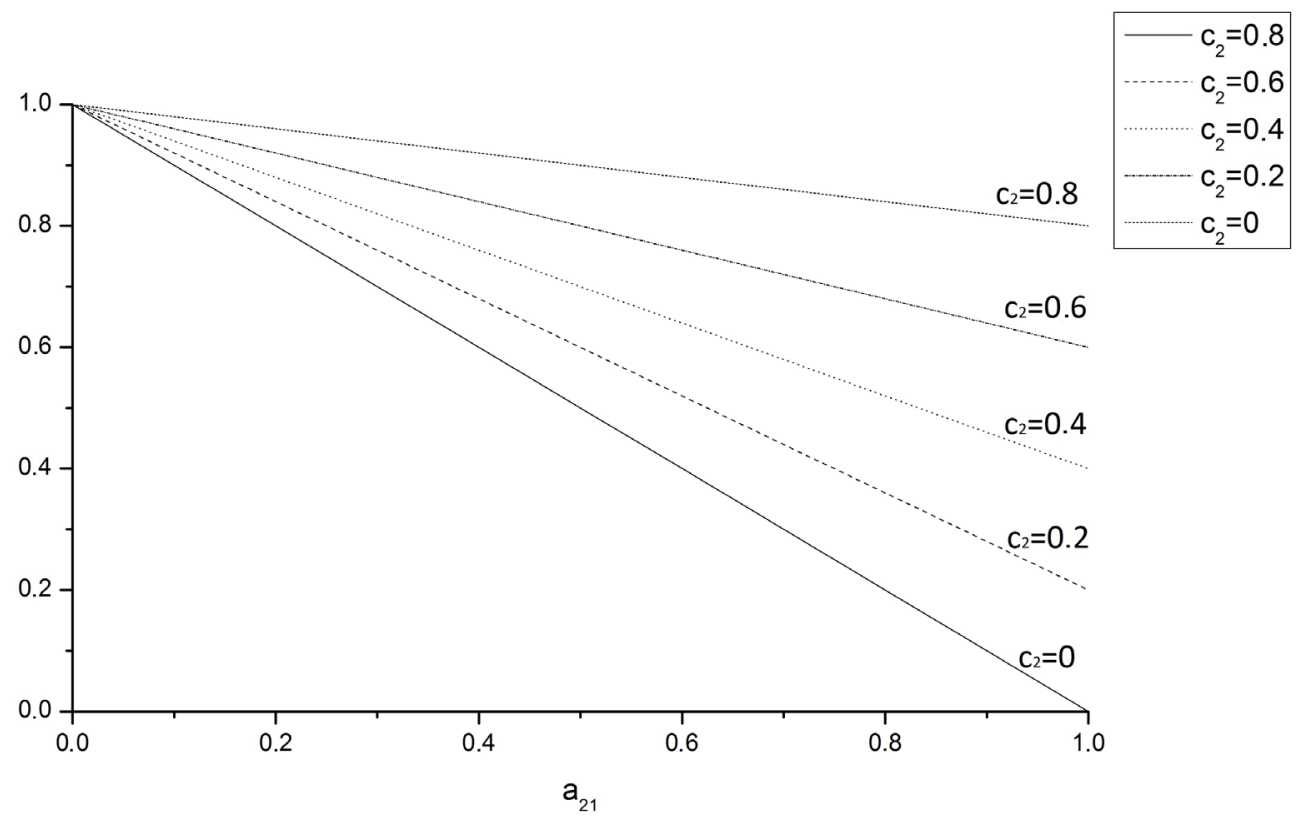

Figure 1. The dependence of the relative energy efficiency $c_{1}=\frac{C_{1}}{Y_{1}}$ from coefficient of energy consumption $a_{21}$ by energy consumers. 


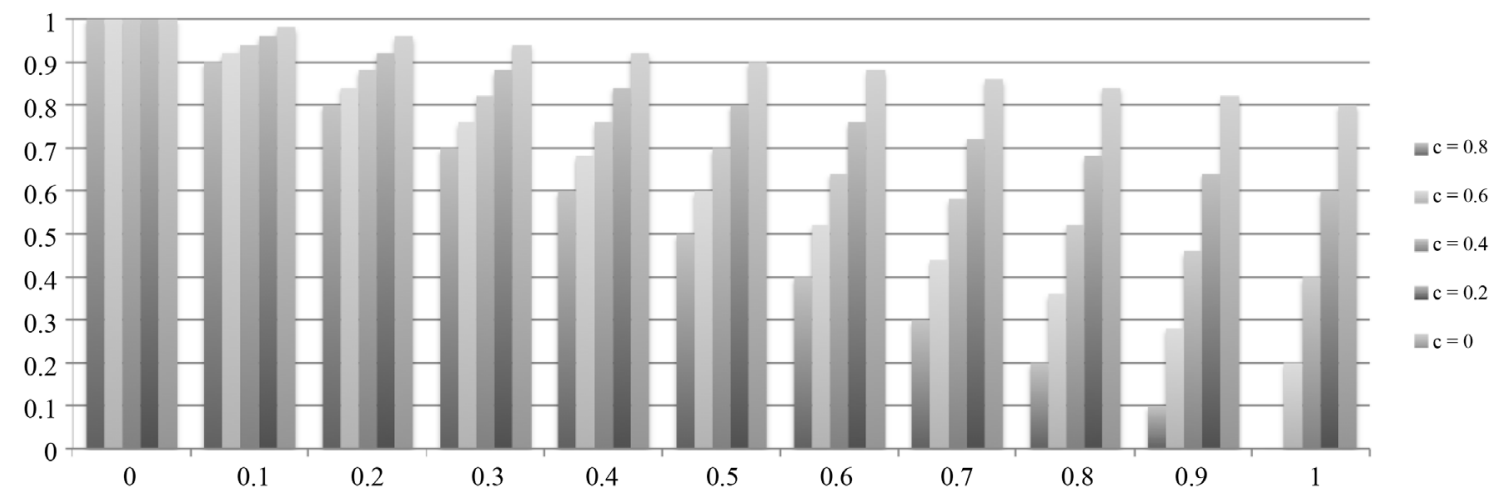

Figure 2. The dependence of the relative energy efficiency $c_{1}=\frac{C_{1}}{Y_{1}}$ from coefficient of energy consumption $a_{21}$ by energy consumers. (Other type of Figure 1 \& Figure 2).

matrix "input-output" in real terms consider production technology through the levels of production and delivery of products. Unit price takes into account the production of energy industries, through the value added components, and the unit price of energy. However, these values are set through external or exogenous indicators, do not derive from the characteristics of the production of the various sectors of the economy. In the previous section we consider a system where the energy industry is one of the economy sectors, and all the manufacturing industry released its own products. In such a model without the introduction of energy efficiency of individual sectors is difficult to consider the correlation of the various sectors of energy and energy efficiency throughout the economy as a whole.

In this section, we would discuss the matrix "expenses" of energy resources and would be determined energy efficiency in various industries. To do this, you need to present the output and supply under the demand of manufacturing industries in terms of energy expended, build a matrix of energy expenses of resources in the economy and get the energy equation.

\subsection{The Output of the Matrix of Energy Expenses on the Basis of the Energy Balance Equation}

For a getting energy expenses matrix we should supplement the production expenses matrix with a separate energy balance equation.

$$
E_{1}+E_{2}+E_{3}+\cdots+E_{i}+\cdots+E_{N}+E_{0}=E
$$

where $E_{i}$ : expenses of energy resources in $i$-th sector, $E_{0}$ : expenses of energy resources directly in the manufacturing of energy resources, $E$ : overall energy resources of the economy.

The system of equations in this case is as follows. There is a system of equations derived from the matrix of production expenses of the $N$ economy sectors with the release of $y_{i}$ and supply of products to consumers $c_{i}$, which is complemented by the equation of energy balance:

$$
\begin{aligned}
& \left(1-a_{11}\right) y_{1}-a_{12} y_{2}-a_{13} y_{3}-\cdots-a_{1 N} y_{N}=c_{1} \\
& -a_{21} y_{1}+\left(1-a_{22}\right) y_{2}-a_{23} y_{3}-\cdots-a_{2 N} y_{N}=c_{2} \\
& \vdots \\
& -a_{N 1} y_{1}-a_{N 2} y_{2}-a_{N 3} y_{3}-\cdots+\left(1-a_{N N}\right) y_{N}=c_{N} \\
& -\frac{E_{1}}{y_{1}} y_{1}-\frac{E_{2}}{y_{2}} y_{2}-\frac{E_{3}}{y_{3}} y_{3}-\cdots-\frac{E_{N}}{y_{N}} y_{N}=-\left(E-E_{0}\right)
\end{aligned}
$$

The last equation is the equation of balance of energy resources obtained identically: the components of the Equation (7) multiplied by the ratio of output himself to himself. Then we can get the ratio of unit expenses of energy resources per unit of product release level as the ratio of energy used in the industry to its 
level of production.

The unknown quantities of Equation (8) are the values of production of industries $y_{1}, y_{2}, \cdots, y_{N}$ and the full value of the energy resources of the economy $E$.

The expenses of energy resources in the industry $E_{i}$ is the component of the energy resources required to ensure the level of output $y_{i}$. Number of energy $e_{i}$, needed on release of a production unit of the $i$ industry is:

$$
e_{i}=\frac{E_{i}}{y_{i}} \text {, or } E_{i}=y_{i} e_{i}
$$

On products delivery to customers, these supplies can be expressed through the supply levels of energy resources. So if consumers are under the supply demand $c_{i}$ products $i$ industry, and the production of each unit of output requires $e_{i}$ number of energy resources, the supply of energy resources to consumers will be:

$$
E_{i}^{(c)}=c_{i} e_{i}
$$

where $c_{i}$ : vector of deliveries level under the demand of the $i$ sector,

$E_{i}^{(c)}$ : vector of energy resources needed to provide the level of demand for $i$-th sector supplies. The value $E_{i}^{(c)}$ represents the energy resources needed for supply households and other final demand sectors.

The matrix equation "expenses-delivery" of energy resources can be expressed by a vector of energy resources by the following equation:

$$
\left(1-D_{j}^{i}\right) E_{i}=E_{j}^{(c)}
$$

where $D_{j}^{i}$ : the matrix of energy resources expenses. Equation (11) is solved for the expenses of energy resources in the $i$-th sector $E_{i}$, required to provide the level of demand for supplies $i$-th sector $E_{i}^{(c)}$.

This matrix can be constructed from the matrix of output-expenses products as follows.

Each element of output-expenses of products $a_{j}^{i}$ determines the ratio of the number of units of the $i$ sector, per unit of products $j$ industry. In order to use this coefficient for the matrix of energy expenses $d_{j}^{i}$, need the coefficient $a_{j}^{i}$ to be multiplied by the ratio of energy needed for production of units $i$ and $j$ industries.

$$
d_{j}^{i}=\frac{e_{j}}{e_{i}} a_{j}^{i}
$$

Then the matrix of energy expenses can be represented as follows:

$$
D_{j}^{i}=\left|\begin{array}{ccccc}
a_{11} & \frac{e_{1}}{e_{2}} a_{12} & \frac{e_{1}}{e_{3}} a_{13} & \cdots & \frac{e_{1}}{e_{N}} a_{1 N} \\
\frac{e_{2}}{e_{1}} a_{21} & a_{22} & \frac{e_{2}}{e_{3}} a_{23} & \cdots & \frac{e_{2}}{e_{N}} a_{2 N} \\
\vdots & \vdots & \vdots & \ddots & \vdots \\
\frac{e_{N}}{e_{1}} a_{N 1} & \frac{e_{2}}{e_{N}} a_{N 2} & \frac{e_{3}}{e_{N}} a_{N 3} & \cdots & a_{N N}
\end{array}\right|
$$

The unit price of each energy sector $v^{j}$ is found by solving the matrix equation, in which the vector-a line of price $v^{j}$ is multiplied by the difference between the identity matrix and the matrix of energy expenses.

$$
v^{j}\left(1-D_{j}^{i}\right)=x^{i}
$$

where $v^{j}$ : the unit price expenses of energy industry $j, x^{i}$ : the unit price of the residual expenses of energy. Similarly, the added value in calculating the price of products on a matrix expenses-release. The system of equations "expenses-delivery" of energy resources and their price is as follows

$$
\begin{gathered}
\left(1-D_{j}^{i}\right) E_{i}=E_{j}^{(c)} \\
v^{j}\left(1-D_{j}^{i}\right)=x^{i}
\end{gathered}
$$


From the matrix of energy expenses $D_{j}^{i}$ and energy supply $E_{i}$ for each industry defined energy resources $E_{i}^{(c)}$ supplies to households and other sectors of final demand. Similarly, by the price of energy in industries $v^{j}$ the residual energy unit price $x^{i}$ is determined.

\subsection{The Matrix of Energy Spending of Two-Sector Economy}

Consider the example of the economy consists of two sectors: agriculture and manufacturing, and we introduce the energy producers that consume products of industry and agriculture, and supply energy to these industries. Each industry produces a certain amount of annual production. Part of the annual production of each industry consumes itself, part direct into another industry, and the rest, supplies to the energy producers. In this model, we have excluded external customers, and equated the right-hand side of Equation (14) to zero.

Energy producers, supply in the energy sector in tons of fuel equivalent (TFE). If the producers of energy produced 300 here in the year, the total expenses of energy is 300 TFE.

Agriculture during a year spent 80 TFE and produced 100 units of agriculture production. For getting specific values of energy expenses this value should be divided by the gross output of agriculture. Then you can get that in agriculture energy expenses per unit of output are $e_{1}=80 / 100=0.8$ (TFE/unit of AG production).

In the manufacturing industry during the year were produced 50 production units, and spent $180 \mathrm{TFE}$, so the unit expenses energy in industry will be: $e_{2}=180 / 50=3.6$.

In addition, we assume that 40 TFE of energy were expended directly in producing energy by themselves, that in relation to the gross level of the overall produced energy is 40/300 $=0.133$ units of the unit energy expenses.

Input-output matrix and energy expenses Aik given in Table 1 which formats following technology. To meet the households demands, agriculture should produce 55 units of agricultural products. To do this, agriculture must have a total output of 100 units. From this amount, 55 products units to supply energy producers, 20 units supply to the manufacturing industry as a raw material for industrial production and 25 production units should remain in agriculture.

The second sector-manufacturing, supply to agriculture 14 units manufacture products (units MA), 6 units of MA use in its industry to maintain production levels and must deliver 30 units of MA to energy producers. To meet these needs and to carrying supply, a second sector should produce 50 units of MA products.

This ratios between expenses and supply in industries depends on the production technology in agriculture and industry, the quantities of required gross output and total consumption. In order to construct a matrix that does not depend on the production and consumption levels, it is necessary to calculate the specific expenses factors and supply relative to the gross output of each industry.

The relative expenses matrix for two sectors, based on natural expenses Table 1 shown in (17). In order to construct energy expenses matrix, necessary to change the expenses matrix in real terms

$$
A_{i k}=\left|\begin{array}{cc}
0.25 & 0.4 \\
0.14 & 0.12
\end{array}\right|
$$

Energy expenses coefficients in every sector: $e_{1}=0.8, e_{2}=3.6$. Then energy expenses matrix will be:

$$
D_{j}^{k}=\left|\begin{array}{cc}
0.25 & 0.4 \frac{0.8}{3.6} \\
0.14 \frac{3.6}{0.8} & 0.12
\end{array}\right|=\left|\begin{array}{ll}
0.25 & 0.84 \\
0.63 & 0.12
\end{array}\right|
$$

Table 1. Matrix input-output and energy expenses. (Unit of output of each industry: AG—Agriculture, MA—Manufacturing, $\mathrm{EP}$ - energy producers are given).

\begin{tabular}{cccccc}
\hline \multirow{2}{*}{ Sectores } & & AG & MA & Final consumption & Gross output \\
\cline { 2 - 6 } & \# & I & II & III & 100 \\
AG (AG units) & I & 25 & 20 & 55 & 50 \\
MA (MA units) & II & 14 & 6 & 30 & 300 \\
EP (TFE) & III & 80 & 180 & 40 & 0.133 \\
The unit expenses of energy & & 0.8 & 3.6 & \\
\hline
\end{tabular}




\section{The Energy Efficiency Equation}

This chapter aims to derive an equation for energy efficiency (EE). To do this, you can use the matrix equation for the energy expenses (15).

The matrix equation for the energy expenses $\left(1-D_{j}^{i}\right) E_{i}=E_{j}^{(c)}$ true for all production or supply levels on demand. Including zero levels supply on demand.

The value $E_{i}^{(c)}$ represents the energy resources required to supply agriculture and manufacturing industry to the households and other sectors of final demand. Consider the solutions of the equation as in the previous two-sector model for the case $E_{i}^{(c)}=0$.

$$
\left(1-D_{j}^{i}\right) E_{i}=0
$$

The solution of this system of equations for energy in the production process exists under the condition equality to zero the determinant of this system of equations.

$$
\operatorname{Det}\left(1-D_{j}^{i}\right)=0
$$

In matrix form this equation will be the following.

$$
\left|\begin{array}{ccccc}
1-a_{11} & -\frac{e_{1}}{e_{2}} a_{12} & -\frac{e_{1}}{e_{3}} a_{13} & \cdots & -\frac{e_{1}}{e_{N}} a_{1 N} \\
-\frac{e_{2}}{e_{1}} a_{21} & 1-a_{22} & -\frac{e_{2}}{e_{3}} a_{23} & \cdots & -\frac{e_{2}}{e_{N}} a_{2 N} \\
\vdots & \vdots & \vdots & \ddots & \vdots \\
-\frac{e_{N}}{e_{1}} a_{N 1} & -\frac{e_{2}}{e_{N}} a_{N 2} & -\frac{e_{3}}{e_{N}} a_{N 3} & \cdots & 1-a_{N N}
\end{array}\right|=0 .
$$

The particular solution of this equation can be obtained by equating to zero the sum of the coefficients of each row of the determinant.

$$
1-\sum_{i=1}^{N} D_{j}^{i}=0 .
$$

If we substitute in this equation general expression for the matrix elements of expenses of energy, we obtain the following relation.

$$
1-\sum_{i=1}^{N} a_{j i} \frac{e_{j}}{e_{i}}=0 .
$$

This system of $j$ equations can be transformed if each equation divided by $e_{j}$.

$$
\sum_{i=1}^{N}\left(\frac{\delta_{j i}}{e_{j}}-\frac{a_{j i}}{e_{i}}\right)=0 .
$$

If we consider values, which are reverse to the energy expenses of production per unit of output as the components vector-column, this equation can be rewritten:

$$
\left(\delta_{j i}-a_{j i}\right) \frac{1}{e_{i}}=0 .
$$

The components of the vector $e_{i}$ have the dimension of the units number of energy per unit of industry output $i$ and determine the energy intensity products. If we introduce the vector $h_{i}$ which is reverse to the vector $e_{i}$ : $h_{i}=\frac{1}{e_{i}}$, then it will determine the number of product of $i$ sector, produced by the unit of energy resources of this industry. This value determines the output energy efficiency of $i$-th sector.

Then Equation (21) can be transformed into the energy efficiency equation:

$$
\left(\delta_{j}^{i}-a_{j}^{i}\right) h_{i}=0 .
$$


Solution of equations system (22) regarding to energy efficiency of industries will exist if the determinant of this equations system is equal to zero. However, the matrix (22) is the production matrix of Equation (1), which determinant by definition can not be equal zero. Equation (1) must have a solution regarding to the output product $y_{i}$ and reverse equation regarding on the supply levels on demand $c_{i}$. Wherein the matrix $\mathbf{1}-\boldsymbol{A}$ of Equation (1) must have an inverse matrix. Therefore, the basic condition of the matrix $\mathbf{1}-\boldsymbol{A}=\delta_{j}^{i}-a_{j}^{i}$-is the existence of the inverse matrix, what can only be in case if the determinant of the matrix is not equal to zero.

Thus, the equations system (22) regarding to energy efficiency without the right part does not have a solution.

Therefore, the initial assumption of the vanishing right-hand side of Equation (19) can not be used. This problem can be solved with the introduction of additional vector-column $q_{j}$ to the right side of Equation (22).

Then the equation must have the form:

$$
\left(\delta_{j}^{i}-a_{j}^{i}\right) h_{i}=q_{j} .
$$

The meaning of the vector $q_{j}$ can be found from the following considerations.

We can rewrite the Equation (23) in the open form:

$$
h_{j}-a_{j}^{i} h_{i}=q_{j} .
$$

This equation shows that the energy efficiency of production or manufacturing energy efficiency of industry is reduced by the expenses of energy caused by the operating expenses in the industry, and other industries connected with the original sector of the matrix coefficients $a_{j}^{i}$ of the technological expenses. Therefore the vector $q_{j}$ defines the actual energy efficiency at the level of final products. We call this parameter as consumer energy efficiency. Since the energy expenses coefficients in the agricultural sector and the manufacturing sector are $e_{1}=$ $0.8, e_{2}=3.6$, we can construct the following two-sector structure of the energy efficiency of the economy.

Energy efficiency of production and consumption for the two-sector economy with the parameters given in Table 2, is defined by the following matrix equation:

$$
\left|\begin{array}{cc}
1-0.25 & -0.4 \\
-0.14 & 1-0.12
\end{array}\right| \times\left|\begin{array}{l}
h_{1} \\
h_{2}
\end{array}\right|=\left|\begin{array}{c}
q_{1} \\
q_{2}
\end{array}\right|
$$

And the equations system:

$$
\begin{aligned}
& 0.75 h_{1}-0.4 h_{2}=q_{1} \\
& -0.14 h_{1}+0.88 h_{2}=q_{2}
\end{aligned}
$$

The values of a consumer energy efficiency, calculated from these equations are: $q_{1}=0.826, q_{2}=0.071$, as given in the Table 2.

Consumer energy efficiency depends on the production efficiency of both sectors. So the first consumer energy efficiency industry or agriculture $q_{1}$ is 0.75 from its production energy efficiency $h_{1}$ minus 0.4 share of production energy efficiency $h_{2}$ of manufacturing. This happened due to the fact that both industries connected with mutual expenses, so energy efficiency of each sector is a multi-variable, depending on the energy efficiency of other industries. Equations (24) allow us to study the mutual influence of the various energy sectors.

Suppose that the production efficiency of manufacturing industry increased by one: $h_{2}+1$. Changing of production EE $h_{2}$ will change consumer EE $q_{1}$ and $q_{2}$ to the values $q_{1}^{\prime}$ and $q_{2}^{\prime}$. Substituting the value $h_{2}+1$ in Equation (24), we obtain

$$
\begin{aligned}
& 0.75 h_{1}-0.4 h_{2}-0.4=q_{1}^{\prime} \\
& -0.14 h_{1}+0.88 h_{2}+0.88=q_{2}^{\prime}
\end{aligned}
$$

Now, from these equations, we minus the Equation (24),

Table 2. The structure of the two-sector energy economy efficiency.

\begin{tabular}{ccc}
\hline & Sector 1 agriculture & Sector II manufacturing industry \\
\hline Expenses of energy $(e)$ & $e_{1}=0.8$ & $e_{2}=3.6$ \\
Industrial EE $\left(h_{i}=1 / e_{i}\right)$ & $h_{1}=1.25$ & $h_{2}=0.28$ \\
Consumer EE $\left(q_{i}\right)$ & $q_{1}=0.826$ & $q_{2}=0.071$ \\
\hline
\end{tabular}




$$
\begin{aligned}
& -0.4=q_{1}^{\prime}-q_{1} \\
& 0.88=q_{2}^{\prime}-q_{2}
\end{aligned}
$$

From these equations is clear that manufacturing consumer energy efficiency $q_{2}^{\prime}$ increase by 0.88 units, and agriculture decreased by 0.4 units.

Similarly, if the energy efficiency of agriculture will increase by one: $h_{1}+1$, then its consumer energy efficiency will increase by 0.75 units, and the manufacturing industry decreased by 0.14 units.

Inverse equation for production energy efficiency and output will be determined by the matrix equation.

$$
h_{j}=\left(\delta_{j}^{i}-a_{j}^{i}\right)^{-1} q_{i}
$$

Matrix, inverse to the production matrix (17) $A_{i k}=\left|\begin{array}{cc}0.25 & 0.4 \\ 0.14 & 0.12\end{array}\right|$, is equal to:

$$
\left(\delta_{j}^{i}-a_{j}^{i}\right)^{-1}=\left|\begin{array}{ll}
1.46 & 0.66 \\
0.23 & 1.24
\end{array}\right|
$$

and the equations system for the energy efficiency of output in the industry will be the following:

$$
\begin{aligned}
& h_{1}=1.46 q_{1}+0.66 q_{2}, \\
& h_{2}=0.23 q_{1}+1.24 q_{2} .
\end{aligned}
$$

Output energy efficiency in the sectors defined by the number of products produced by each industry per unit of energy, consumed in this sector. It is defined by a linear combination of consumer energy efficiency of both sectors with the appropriate coefficients.

By energy efficiency definition, dimension of this value is equal to the dimension of output unit per energy unit. Therefore, compare the different sectors of energy efficiency in bulk does not make sense, because they are measured in different units. To make such a comparison, it is necessary to determine the monetary value of energy productivity, as the products value produced with energy consumption.

\subsection{The Equation for the Expenses of Energy Production Industries}

The price of production sectors defined by the equation:

$$
p^{i}=v^{j}\left(\delta_{j}^{i}-a_{j}^{i}\right)^{-1},
$$

where $p^{i}, v^{j}$ vectors-line, prices and value-added products, respectively.

If you multiply the product price on the energy efficiency of its production $h_{j}=\left(\delta_{j}^{i}-a_{j}^{i}\right)^{-1} q_{i}$, you get output energy efficiency in the industry in terms of value or expenses of energy efficiency production or produced goods value per energy unit:

$$
p^{j} h_{j}=\sum_{k=1}^{N} \sum_{i=1}^{N} v^{k}\left(\delta_{k}^{j}-a_{k}^{j}\right)^{-1}\left(\delta_{j}^{i}-a_{j}^{i}\right)^{-1} q_{i}
$$

In these equations is not assume index summation $j$.

Expenses of consumer energy efficiency is equal to the multiplication of the added value $v^{j}$ on consumer energy efficiency $q_{j}$ :

$$
v^{j} q_{j}=\sum_{k=1}^{N} \sum_{i=1}^{N} p^{k}\left(\delta_{k}^{j}-a_{k}^{j}\right)\left(\delta_{j}^{i}-a_{j}^{i}\right) h_{i}
$$

\subsection{Using the Template}

If the price of the industry product $p^{j}=v^{i}\left(\delta_{i}^{j}-a_{i}^{j}\right)^{-1}$ multiply from the right on the consumer energy efficiency of the industry $q_{j}=\left(\delta_{j}^{i}-a_{j}^{i}\right) h_{i}$, we get the expression:

$$
p^{j} q_{j}=v^{i}\left(\delta_{i}^{j}-a_{i}^{j}\right)^{-1}\left(\delta_{j}^{k}-a_{j}^{k}\right) h_{k} .
$$


In this expression we will sum over the same indices. The multiplication $t$ of the left and right sides must sum over the index $j$. The multiplication of the direct and inverse release matrix give us the identity matrix, it can be written:

$$
p^{j} q_{j}=v^{i} \delta_{i}^{k} h_{k}=v^{i} h_{i} .
$$

This economic identity for the energy efficiency: the amount of the multiplication of products price on the consumer energy efficiency is equal to the sum of the multiplications of value added on production efficiency.

\subsection{Correlation of Energy Efficiency Sectors}

Since the various economy sectors technologically linked through the expenses matrix, the energy efficiency of each sector should correlate and influence on the energy efficiency of other industries. Changing of the energy efficiency of one industry must inevitably lead to changes in energy efficiency of other sectors.

Consider the example of the energy efficiency correlation on EE equations of two sectors economy (24). Divide the first and the second Equation (24) on $h_{1}$ and $h_{2}$, respectively, and introduce the value of the relative energy efficiency $h_{21}=h_{2} / h_{1}$ and the relative consumer energy efficiency as its ratio to industrial energy efficiency: $q_{1}^{\prime}=q_{1} / h_{1}$ and $q_{2}^{\prime}=q_{2} / h_{2}$ as a result the Equation (24) will be

$$
\begin{aligned}
& 0.75-0.4 h_{21}=q_{1}^{\prime} \\
& -\frac{0.14}{h_{21}}+0.88=q_{2}^{\prime}
\end{aligned}
$$

The dependence of the relative consumer EE of two industries $q_{1}^{\prime}$ and $q_{2}^{\prime}$ from the relative production EE of the two sectores $h_{21}=h_{2} / h_{1}$ is shown on the Figure $3 \&$ Figure 4 . From these dependencies we can get a series of interesting data.

1) If $\mathrm{EE}$ of the second sector increases, the relative energy efficiency of the first sector falls from 0.7 to 0 while the second sector EE increases from 0 to 0.8 .

2) Change limits of relative EE of two sectores $h_{21}=h_{2} / h_{1}$ set from 0.2 to 1.9. Thus, value of energy efficiency industry cannot be more than in 5 times more than other energy efficiency industry.

3) The maximum value of the first industry consumer EE cannot be more than 0.7 and the second more than 0.8 .

These ratios are determined by the coefficients of expenses matrix. For other technology matrices of economy sectors, these relations will change.

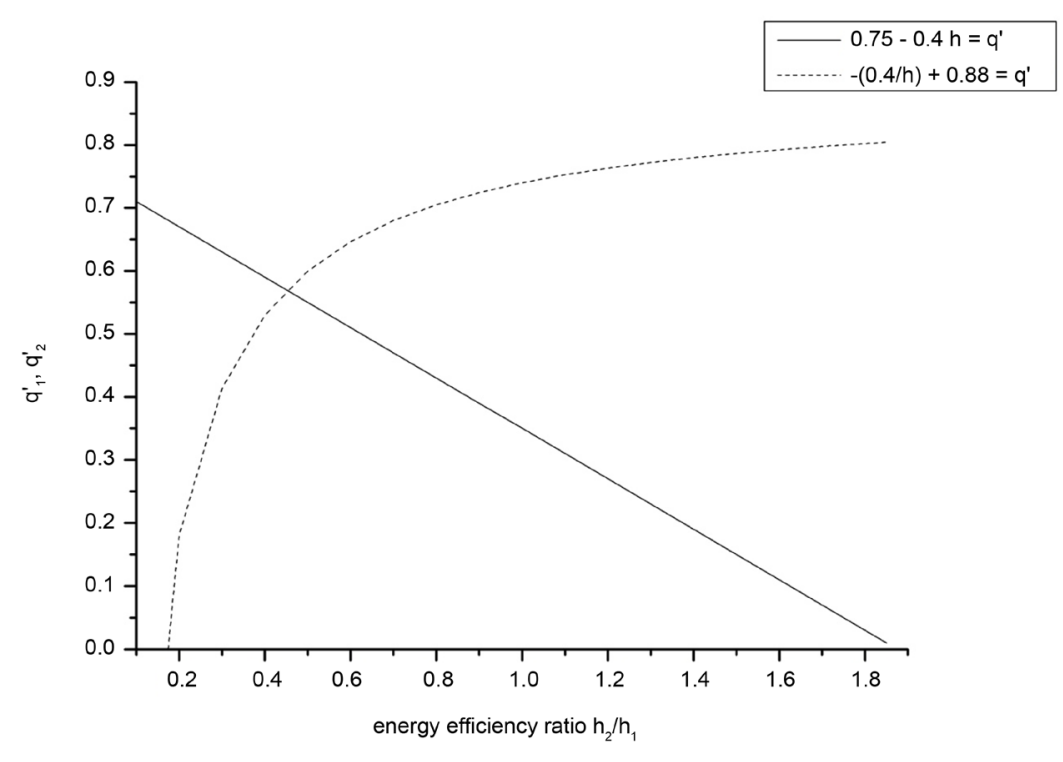

Figure 3. The relative two sectors consumption of the EE: $q_{1}^{\prime}$ (series 1) and $q_{2}^{\prime}$ (series 2) vs. relative industries EE of $h_{21}=h_{1} / h_{2}$. 


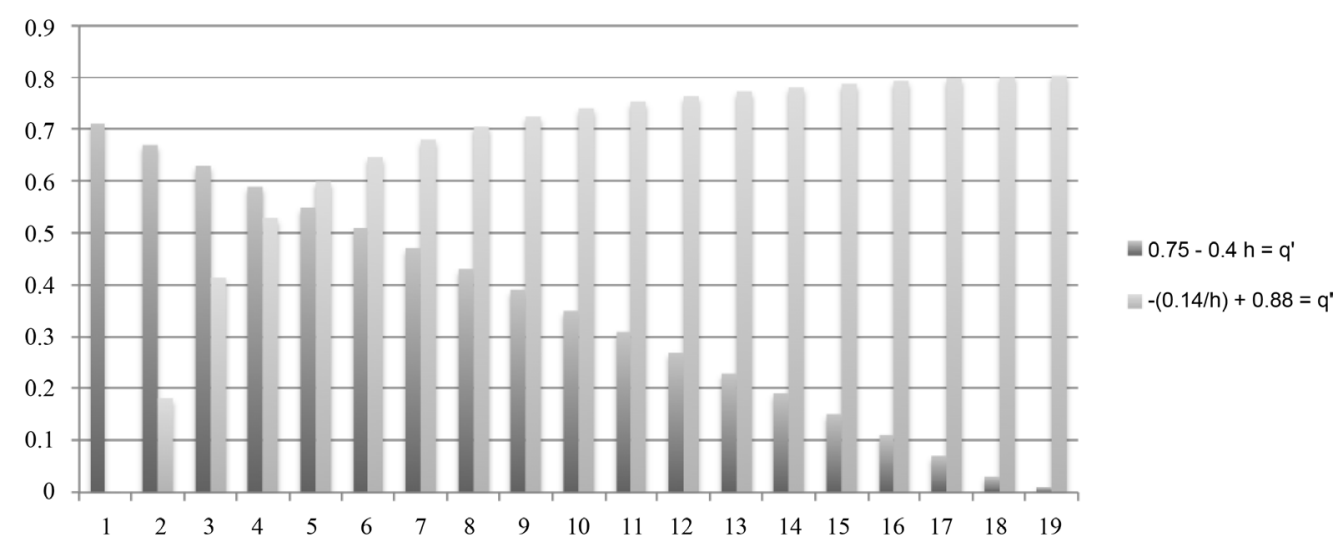

Figure 4. The relative two sectors consumption of the EE: $q_{1}^{\prime}$ (series 1) and $q_{2}^{\prime}$ (series 2) vs. relative industries EE of $h_{21}=h_{1} / h_{2}$. (Other type of Figure 3).

\section{Conclusion}

The paper proposed the concept of "energy saving", defined as the potential energy delivery to external customers in the economy structure by saving energy in producing goods industries, an energy efficiency equation, and derived new concepts: "industrial and consumer energy efficiency" as industries energy efficiency in the levels of production and consumption of their products. A matrix equation for calculating and analyzing their energy efficiency industry, taking into account the mutual influence of different industries on each other were received. Analyzes the effect of the correlation of consumer and industrial energy efficiency.

Specific calculations of these values and correlations should be carried out for economic systems, for which product flows between industries, their output and demand under supply, as well as the expenses of energy in industries are known.

\section{References}

[1] Grigoryev, L.M. (2010) We Need New Incentives to Reduce the Energy Intensity of GDP by 2020, 40 Percent. In: Grigoryev, L.M. and Kondratiev, S.V., Eds., Russian Daily, №5322 (243).

[2] ISO 50001: 2011 Energy Management Systems—-Requirements with Guidance for Use. International Organization for Standartization, Geneva, 2011, 22 p. http://www.iso.org/iso/catalogue_detail?csnumber=51297

[3] Lozenko, V.K. (2012) The Development of Institutional Arrangements-A Key Factor in the Progress of Innovation in the Management of Energy Efficiency. In: Lozenko V.K. and Ageev M.K., Eds., Controlling, №1.

[4] Kustov, E.F. (2005) Analytical Economics. Pershyn, Tambov, 504 p.

[5] Leontiev, V.K. (1990) Economic Essays. Political Literature Publishing House, Moscow, 319 p.

[6] Kustov, E.F. and Kustov, M.E. (2011) Environmental Analysis. Lap Lambert Academic Publishing GmbH \& Co. KG, Saarbrucken German, 260 p.

[7] Kustov, E.F. (2012) Economy and Corruption. Lap-Lambert Academic Publishing GmbH \& Co. KG, Saarbrucken German, 580 p.

[8] Kustov E.F. (2011) Matrix Method of Analysis of the Impact of Corruption on the Economy. Economic Analysis. Theory and Practice, 31, 47-55.

[9] Kustov, E.F., Lozenko, V.K. and Kuzavko, A.S. (2011) Matrix Models for the Analysis of the Investment Management Industry. Transportation Business in Russia, 37-41.

[10] Kustov, E.F., Dli, M.I. and Kuzavko, A.S. (2011) Matrix Method of Analysis of the Two Sector of the Economy by the Example of the Financial and Real Sectors of the Smolensk Region. Financial Analytics: Problems and Solutions, 38, $2-11$.

[11] Kustov, E.F. (2012) The Energy Economy. Methods for Calculating the Energy Efficiency and Conservation, LAP LAMBERT Academic Publishing GmbH \& Co. KG, Saarbrucken German, 355 p.

[12] Kustov, E.F., Dli, M.I. and Kuzavko, A.S. (2012) Matrix Method of Analysis of the Regional Economy. MEI Bulletin, 161-165. 